This is the peer reviewed version of the following article: S. Fredrich, R. Göstl, M. Herder, L. Grubert, S. Hecht, Angew. Chem. Int. Ed. 2016, 55, 1208, which has been published in final form at http://onlinelibrary.wiley.com/doi/10.1002/anie.201509875/abstract. This article may be used for noncommercial purposes in accordance with Wiley Terms and Conditions for Self-Archiving.

\title{
Switching Diarylethenes Reliably in Both Directions with Visible Light
}

Sebastian Fredrich, Robert Göstl, Martin Herder, Lutz Grubert, and Stefan Hecht*

\begin{abstract}
A diarylethene photoswitch was covalently connected to two small triplet sensitizer moieties in a conjugated and nonconjugated fashion and the photochromic performance of the resulting compounds was investigated. In comparison with the parent diarylethene (without sensitizers) and one featuring saturated linkages, the conjugated photoswitch offers superior fatigue resistance upon visible-light excitation due to effective triplet energy transfer from the biacetyl termini to the diarylethene core. Our design makes it possible to switch diarylethenes with visible light in both directions in a highly efficient and robust fashion based on extending $\pi$-conjugation and by-product-free ring-closure via the triplet manifold.
\end{abstract}

\section{Introduction}

Over the past years molecular switches[1] have received much attention due to their promising role as active control elements in functional materials and devices.[2] The unique characteristic of a switch as compared to a fuse lies in its reversibility. However, in order to exploit this distinguishing feature truly robust systems associated with a pronounced fatigue resistance - the capacity to undergo many switching cycles without considerable degradation - are needed. Another important practical demand relates to the necessity to operate the switch (in both directions) by visible light,[3] for example to reduce harmful effects of high-energy UV light and to ensure deeper penetration into the (bio)material.

Most families of molecular switches rely on two distinct mechanisms: Either E/Z isomerization of a double bond, involving a significant geometrical change, or $6 \pi$ electrocyclization of a triene system that enables strong electronic modulation. Azobenzenes,[4] the most prominent family in the former class, are known to perform reliably and can be addressed directly by visible-light excitation.[5] In contrast, diarylethenes,[6] representing arguably the most attractive family in the latter class, require an elaborate design to achieve high fatigue resistance. Whereas in the solid state the molecular environment of a single crystal allows for thousands of switching cycles without pronounced degradation upon alternating irradiation with UV and 
visible light,[7] highly repetitive switching remains a critical issue in solution.[ 8] To meet this challenge, the two main strategies involve incorporation of electron-withdrawing groups[9] and steric hindrance[10] to prevent formation of a common by-product caused by a UV-induced irreversible photoreaction of the ringclosed isomer. In addition to the issue of fatigue resistance, several attempts have been made to red-shift the absorption of the open form in order to utilize visible light also for ring-closing. This issue has been addressed directly by elongating the conjugated $\pi$-system[11] and indirectly by attaching (rather extended) antenna chromophores.[12] Here we show that both of these critical aspects can be addressed simultaneously by attaching small triplet-sensitizing moieties to a diarylethene core via a $\pi$-conjugated linkage. Thus, our design takes advantage of both the deliberate manipulation of the singlet-triplet transition and the bathochromically shifted absorption due to the extended $\pi$-system to achieve ring-closure via the triplet manifold upon visiblelight excitation.

Our approach is based on recent findings showing that byproduct formation occurs exclusively from an excited singlet state[9c,13] and hence ring-closure via the triplet manifold represents an attractive strategy to circumvent this detrimental side reaction. In fact, triplet sensitization of diarylethenes has previously been reported using transition-metal complexes[14] as well as solely organic[9c,15] triplet sensitizers in either intermolecular or intramolecular fashion. Indeed, formation of the by-product during the conversion of a parent diarylethene 10 to the closed isomer 1c could be avoided by intermolecular triplet sensitization using an excess of biacetyl (Scheme 1).[9c] Although biacetyl offers a high intersystem crossing efficiency of practically $100 \%[16]$ and a high-energy triplet state able to sensitize the open form of the diarylethene, it suffers from an extremely low extinction coefficient of $20 \mathrm{M}^{-1} \mathrm{~cm}^{-1}$ at $400 \mathrm{~nm}$ originating from the corresponding symmetry-forbidden $n \rightarrow \pi^{*}$ transition. As a result, a large excess of biacetyl (250 equivalents) was needed to ensure sufficient absorption at $400 \mathrm{~nm}$ and local concentration in the bimolecular sensitization process. In order to avoid this concentration dependence we have covalently connected the biacetyl and diarylethene units, using saturated and $\pi$-conjugated linkages to afford diarylethenes $\mathbf{2}$ and $\mathbf{3}$, respectively (Scheme 1).

To synthesize target compounds $\mathbf{2}$ and $\mathbf{3}$ the modular route developed by Feringa and co-workers[17] was adapted by attaching the appropriate biacetyl-substituted phenyl residues to the preformed diarylethene core via a Suzuki cross-coupling reaction. The corresponding biacetyl-substituted phenylbromides were readily available from diethyl ketal monoprotected biacetyl via aldol condensation with benzaldehydes. In the case of the saturated linker, the double bond was reduced by transfer hydrogenation. Suzuki cross-coupling of the phenyl bromides to 1,2-bis(2-chloro-5-methylthien-3-yl)cyclopentene involving in situ borylation followed by final deprotection provided photoswitches $\mathbf{2}$ and $\mathbf{3}$ as their open isomers. For further details on the synthetic procedures and compound characterization, consult the Supporting Information.

The absorption spectra of the saturated photoswitch $\mathbf{2}$ closely resemble those of the parent diarylethene $\mathbf{1}$ (Figure 1). The presence of the (decoupled) biacetyl moiety is revealed by a weak shoulder reaching into the visible range of the spectrum. In contrast, the absorption band of the unsaturated derivative 30 is strongly bathochromically shifted to $\lambda(\max )=390 \mathrm{~nm}$, as compared to $\lambda(\max )=282 \mathrm{~nm}$ (for $\mathbf{2 0}$ ), due to the elongated 
$\pi$-system and its push-pull character originating from the electron-rich thiophene and the electronwithdrawing diketone units. Most importantly, the molar absorptivity at $400 \mathrm{~nm}$ increases by about 1000 -fold, rendering the excitation of photoswitch $\mathbf{3 o}$ in the visible range a lot more efficient than that of $\mathbf{2 0 .}$

Irradiation of an acetonitrile solution of $\mathbf{2 0}$ at $\lambda(\mathrm{irr})=313 \mathrm{~nm}$ results in quantitative photoconversion to the closed isomer $\mathbf{2 c}$, which displays a characteristic visible absorption band at $\lambda(\max )=526 \mathrm{~nm}$ similar to 10 and typical for ring-closed diarylethenes. Analogously, irradiation of the conjugated photoswitch $\mathbf{3 o}$ in acetonitrile at $\lambda$ (irr) $=313 \mathrm{~nm}$ leads to formation of the respective ring-closed isomer $3 \mathbf{c}$. During ring-closure, the band at $\lambda(\max )=390 \mathrm{~nm}$ diminishes and two new bands appear: One at $\lambda(\max )=330 \mathrm{~nm}$ and the other one in the visible range at $\lambda(\max )=608 \mathrm{~nm}$. In comparison with $\mathbf{2 c}$, the latter is strongly red-shifted by $82 \mathrm{~nm}$ (Figure 1), again illustrating the extended $\pi$-conjugation. The photoconversion, that is, the amount of isomer $3 \mathbf{c}$ that can be attained in the photostationary state (PSS) upon ring-closure at $\lambda$ (irr) $=313 \mathrm{~nm}$, is lower than in the case of $\mathbf{2 0} \rightarrow \mathbf{2 c}$ due to an increasing absorption of the ring-closed isomer upon irradiation at $313 \mathrm{~nm}$ (Table 1).

Because of the large bathochromic shift of 3o, it should also be possible to induce ring-closure in the blue region of the visible spectrum. Indeed, when irradiation at $\lambda$ (irr) $=405 \mathrm{~nm}$ was employed, complete photoconversion of $\mathbf{3 o}$ to $\mathbf{3 c}$ is observed, whereas $\mathbf{1 0}$ and $\mathbf{2 0}$ do not undergo any detectable photocyclization under these conditions. This is most likely due to the lack of absorbance of $\mathbf{1 0}$ and the negligible extinction coefficient of 20 at $\lambda$ (irr) $=405 \mathrm{~nm}$ as well as the stronger absorbance of the formed closed isomers at the same wavelength, thus favoring cycloreversion instead. The significant effect of the conjugated linkage on shifting a high extinction band into the visible range has also been verified independently for model compounds (see Figure S6 in the Supporting Information). Furthermore, the presence of oxygen in solution has a considerable effect on the time required to reach the PSS in the irradiation of $\mathbf{3 0}$, while irradiations of 10 and 20 were not affected.

To quantify the efficiencies of the photochemical ring opening and ring-closure reactions of $\mathbf{2}$ and $\mathbf{3}$, quantum yields were determined both in the presence and absence of oxygen (Table 1). The quantum yields for ringclosure of 20 upon $\lambda$ (irr) $=313 \mathrm{~nm}$ irradiation are comparable to those of the parent dithienylethene 1 $[9 \mathrm{c}, 18]$ and are not dependent on the presence of oxygen, similar to most conventional diarylethenes. For the conjugated photoswitch 30 a different behavior was observed. Upon irradiation of a degassed solution of 30 at $\lambda($ irr $)=405 \mathrm{~nm}$ a quantum yield of $30 \%$ was determined, whereas in the presence of oxygen it drastically decreased to $0.9 \%$. This finding is a clear indication for the population of an excited triplet state of $\mathbf{3 o}$, which is quenched by molecular oxygen and thereby acts as a singlet-oxygen sensitizer.[19] In the meantime not only the quantum yield but also the fatigue resistance decreases in the presence of air primarily due to formation of reactive singlet oxygen, which yields various oxidation by-products.[20] A similar tendency is observed for irradiation of $\mathbf{3 o}$ at $\lambda($ irr $)=313 \mathrm{~nm}$; however, the generally lower quantum yields compared to those upon irradiation at $\lambda$ (irr) $=405 \mathrm{~nm}$ indicate a less efficient population of the reactive triplet excited state. A significantly reduced intersystem-crossing quantum yield compared to that of the parent biacetyl is not likely since comparable values have been determined for benzyl with $\varphi($ ISC $)=0.92 .[21]$ Note that the 
effective quantum yield for the intermolecular sensitization of $\mathbf{1 0}$ to $1 \mathbf{c}$ using excess biacetyl upon irradiation at $\lambda$ (irr) $=405 \mathrm{~nm}$ was $36 \%$, which is comparable to the value obtained for the ring-closure of $3 \mathbf{0}$. No trace of 1c was observed in the experiments without biacetyl or in the presence of oxygen at $\lambda$ (irr) $=405 \mathrm{~nm}$.

The ring-closed isomer 3c can readily be converted back to its open form $\mathbf{3 o}$ by irradiation of the longwavelength band at $\lambda>500 \mathrm{~nm}$. The associated quantum yield of the cycloreversion reaction is rather low and is independent of the presence of oxygen. As earlier work has shown that the cycloreversion in the excited triplet state is inhibited due to large thermal barriers,[22] it is likely that the ring-opening reaction of 3c proceeds in the singlet state. The fact that the quantum yield for the ring-opening of $\mathbf{3} \mathbf{c}$ is lower than that of the ring-opening of the saturated compound $\mathbf{2 c}$ and the parent diarylethene $1 \mathbf{c}$ may be explained by a competing population of the unreactive triplet as well as the generally less efficient cycloreversion in the excited singlet state as a consequence of the elongated $\pi$-system.[23] This in fact illustrates an intrinsic drawback of our approach as the enhanced fatigue resistance in the triplet manifold is accompanied by a reduced ring-opening efficiency.

To gather further evidence for the involvement of a triplet state in the cyclization of $\mathbf{3 0}$ oxygen was replaced by another quencher, for which the concentration could easily be adjusted. Anthracene was chosen because it features a low-lying triplet state, which (in the absence of oxygen) thermally relaxes without any by-product formation, and its absorption spectra display no extinction at the irradiation wavelength $(\lambda(\operatorname{irr})=405 \mathrm{~nm})$. We measured the quantum yield of the ring-closure of $\mathbf{3 o}$ at varying concentrations of the anthracene quencher and the resulting Stern-Volmer analysis showed a linear relationship (see Figure S9 in the Supporting Information), providing clear evidence that cyclization proceeds via a triplet state.

One advantage of triplet sensitization is the possible use of light with lower energy in contrast to conventional diarylethenes. As UV light is known to induce side reactions arising from the ring-closed isomer, the fatigue resistance of photoswitch 3 should be improved. To investigate this aspect, switching cycles consisting of alternating ring-closure at $\lambda$ (irr) $=405 \mathrm{~nm}$ and ring-opening with $\lambda$ (irr) $>500 \mathrm{~nm}$ were carried out (Figure 2). Repeatedly the long-wavelength band of the closed isomer at $\lambda(\max )=608 \mathrm{~nm}$ could be reestablished, indicating no loss of material as the same amount of ring-closed isomer is consistently regenerated over the course of many switching cycles. This is in strong contrast to conventional diarylethenes, such as parent dithienylethene 1, which upon an increasing number of switching cycles exhibit a continuous decay of the visible band indicating an increasing loss of material due to by-product formation (see Figure S10 in the Supporting Information). Note that the number of cycles that can conveniently be obtained for diarylethene $\mathbf{3}$ is limited by the rather poor cycloreversion efficiency necessitating extended irradiation times for backswitching, which was not pushed to completion for time reasons (see varying minima in Figure 2).

For a true performance test $\mathbf{3}$ was exposed to long-time irradiation in order to force by-product formation (Figure 3). Even after extended continuous irradiation with $\lambda$ (irr) $=405 \mathrm{~nm}$ light of high intensity (1000W Xe lamp equipped with an interference filter) no sign of degradation was observed as judged by the intensity of the long-wavelength absorption of the closed isomer. In contrast, diarylethene 1 shows a fast decay upon irradiation at $\lambda$ (irr) $=313 \mathrm{~nm}$ as a result of the formation of the well-known by-product from the closed 
isomer.[9c] A similar behavior was observed in the case of the saturated switch $2(313 \mathrm{~nm})$, which does not ring-close via the triplet excited state.

Even upon prolonged UV irradiation at $\lambda(\operatorname{irr})=313 \mathrm{~nm} 3$ proves to be significantly more stable than diarylethenes 1 and 2 (Figure 3). Clearly, upon excitation at $\lambda($ irr) $=313 \mathrm{~nm}$ the triplet pathway plays an important role and helps to avoid byproduct formation. Apart from this, it is important to note that diarylethene 3 can be used to generate singlet oxygen selectively, that is, only by irradiation of the ringopened isomer $3 \mathbf{s}$ but not from $\mathbf{3 c}$.

In summary, by attaching triplet-sensitizing units to a diarylethene we have been able to significantly improve its photoswitching performance. Specifically, our improved photoswitch 3 can reliably be operated with visible light only and shows negligible fatigue even after extended irradiation times. Besides extending the conjugated $\pi$-system our design is based on a deliberate use of the triplet manifold, which should prove beneficial for the development of improved photoswitches[3] as well as photoswitchable sensitizers.[19] Current efforts are devoted to designing alternative sensitizer-switch constructs to optimize the ring-opening quantum yields.

\section{Acknowledgements}

The Generous support by the German Research Foundation (DFG via SFB 658, project B8), the European Research Council (ERC via ERC-2012-STG_308117 “Light4Function"), and the European Commission (via ITN "iSwitch") is gratefully acknowledged. We thank BASF AG, Bayer Industry Services, and Sasol Germany for generous donations of chemicals.

\section{Keywords}

diarylethenes $\cdot$ photochromism $\cdot$ sensitizers $\cdot$ singlet oxygen

\section{References}

[1] Representative recent overviews are given in: a) Molecular Switches (Eds.: B. L. Feringa, W. R. Browne), $2^{\text {nd }}$ ed., Wiley- VCH, Weinheim, 2011; b) New Frontiers in Photochromism (Eds.: M. Irie, Y. Yokoyama, T. Seki) Springer, Japan, 2013.

[2] For reviews, see: a) J. M. Abendroth, O. S. Bushuyev, P. S. Weiss, C. J. Barrett, ACS Nano 2015, 9, 77467768; b) E. Orgiu, P. Samorì, Adv. Mater. 2014, 26, 1827-1845; c) M.-M. Russew, S. Hecht, Adv. Mater. 2010, 22, 3348-3360.

[3] D. Bléger, S. Hecht, Angew. Chem. Int. Ed. 2015, 54, 11338-11349; Angew. Chem. 2015, 127, 1149411506.

[4] For a review, see: a) H. M. D. Bandara, S. C. Burdette, Chem. Soc. Rev. 2012, 41, 1809-1825.

[5] a) R. Siewertsen, H. Neumann, B. Buchheim-Stehn, R. Herges, C. Näther, F. Renth, F. Temps, J. Am. Chem. Soc. 2009, 131, 15594-15595; b) A. A. Beharry, O. Sadovski, G. A. Woolley, J. Am. Chem. Soc. 2011, 133, 19684-19687; c) D. Bléger, J. Schwarz, A. M. Brouwer, S. Hecht, J. Am. Chem. Soc. 2012, 134, 2059720600. 
[6] For a comprehensive recent review, see: M. Irie, T. Fukaminato, K. Matsuda, S. Kobatake, Chem. Rev. 2014, 114, 12174-12277.

[7] a) M. Irie, K. Uchida, T. Eriguchi, H. Tsuzuki, Chem. Lett. 1995, 10, 899-900; b) S. Kobatake, T. Yamada, K. Uchida, N. Kato, M. Irie, J. Am. Chem. Soc. 1999, 121, 2380-2386; c) S. Kobatake, M. Yamada, T. Yamada, M. Irie, J. Am. Chem. Soc. 1999, 121, 8450 - 8456; d) H. Jean-Ruel, R. R. Cooney, M. Gao, C. Lu, M. A. Kochman, C. A. Morrison, R. J. D. Miller, J. Phys. Chem. A 2011, 115, 13158-13168.

[8] M. Hanazawa, R. Sumiya, Y. Horikawa, M. Irie, J. Chem. Soc. Chem. Commun. 1992, 206-207.

[9] a) J. J. D. de Jong, L. N. Lucas, R. Hania, A. Pugzlys, R. M. Kellogg, B. L. Feringa, K. Duppen, J. H. van Esch, Eur. J. Org. Chem. 2003, 1887-1893; b) Y.-C. Jeong, D. G. Park, E. Kim, K.-H. Ahn, S. I. Yang, Chem. Commun. 2006, 1881-1883; c) M. Herder, B. Schmidt, L. Grubert, M. Pätzel, J. Schwarz, S. Hecht, J. Am. Chem. Soc. 2015, 137, 2738-2747.

[10] a) M. Irie, T. Lifka, K. Uchida, S. Kobatake, Y. Shindo, Chem. Commun. 1999, 747-750; b) Y.-C. Jeong, S. I. Yang, E. Kim, K.-H. Ahn, Tetrahedron 2006, 62, 5855-5861; c) Y.-C. Jeong, D. G. Park, I. S. Lee, S. I. Yang, K.-H. Ahn, J. Mater. Chem. 2009, 19, 97-103; d) P. D. Patel, I. A. Mikhailov, K. D. Belfield, A. E. Masunov, Int. J. Quantum Chem. 2009, 109, 3711-3722.

[11] a) G. M. Tsivgoulis, J.-M. Lehn, Chem. Eur. J. 1996, 2, 1399 - 1406; b) O. Tosic, K. Altenhoner, J. Mattay, Photochem. Photobiol. Sci. 2010, 9, $128-130$.

[12] a) R. T. F. Jukes, V. Adamo, F. Hartl, P. Belser, L. De Cola, Inorg. Chem. 2004, 43, 2779-2792; b) T. Fukaminato, T. Hirose, T. Doi, M. Hazama, K. Matsuda, M. Irie, J. Am. Chem. Soc. 2014, $136,17145-17154$.

[13] D. Mendive-Tapia, A. Perrier, M. J. Bearpark, M. A. Robb, B. Lasorne, D. Jacquemin, Phys. Chem. Chem. Phys. 2014, 16, 18463-18471.

[14] For reviews, see: a) E. C. Harvey, B. L. Feringa, J. G. Vos, W. R. Browne, M. T. Pryce, Coord. Chem. Rev. 2015, 282-283, 77-86; b) F. Jukes, V. Adamo, F. Hartl, P. Belser, L. De Cola, Coord. Chem. Rev. 2005, $249,1327-1335$.

[15] a) G. Favaro, U. Mazzucato, F. Ortica, P. Smimmo, Inorg. Chim. Acta 2007, 360, 995-999; b) T. Fukaminato, T. Doi, M. Tanaka, M. Irie, J. Phys. Chem. C 2009, 113, 11623-11627; c) R. Murata, T. Yago, M. Wakasa, Bull. Chem. Soc. Jpn. 2011, 84, 1336-1338; d) R. Murata, T. Yago, M. Wakasa, J. Phys. Chem. A 2015, 119, 11138-11145.

[16] T. N. Singh-Rachford, F. N. Castellano, J. Phys. Chem. A 2009, 113, 5912-5917.

[17] a) L. N. Lucas, J. van Esch, R. M. Kellogg, B. L. Feringa, Chem. Commun. 1998, 2313-2314; b) L. N. Lucas, J. J. D. de Jong, J. H. van Esch, R. M. Kellogg, B. L. Feringa, Eur. J. Org. Chem. 2003, $155-166$.

[18] R. Göstl, B. Kobin, L. Grubert, M. Pätzel, S. Hecht, Chem. Eur. J. 2012, 18, 14282-14285.

[19] A photoswitchable singlet-oxygen sensitizer based on a diarylethene linked to a palladium porphyrin has recently been described in: L. Hou, X. Zhang, T. C. Pijper, W. R. Browne, B. L. Feringa, J. Am. Chem. Soc. 2014, 136, 910-913. 
[20] K. Higashiguchi, K. Matsuda, T. Yamada, T. Kawai, M. Irie, Chem. Lett. 2000, 29, 1358-1359.

[21] A. A. Lamola, G. S. Hammond, J. Chem. Phys. 1965, 43, 2129-2134.

[22] M. T. Indelli, S. Carli, M. Ghirotti, C. Chiorboli, M. Ravaglia, M. Garavelli, F. Scandola, J. Am. Chem. Soc. 2008, 130, 7286-7299.

[23] a) M. Irie, T. Eriguchi, T. Takada, K. Uchida, Tetrahedron 1997, 53, 12263-12271; b) A. T. Bens, D. Frewert, K. Kodatis, C. Kryschi, H.-D. Martin, H. P. Trommsdorff, Eur. J. Org. Chem. 1998, 2333-2338. 

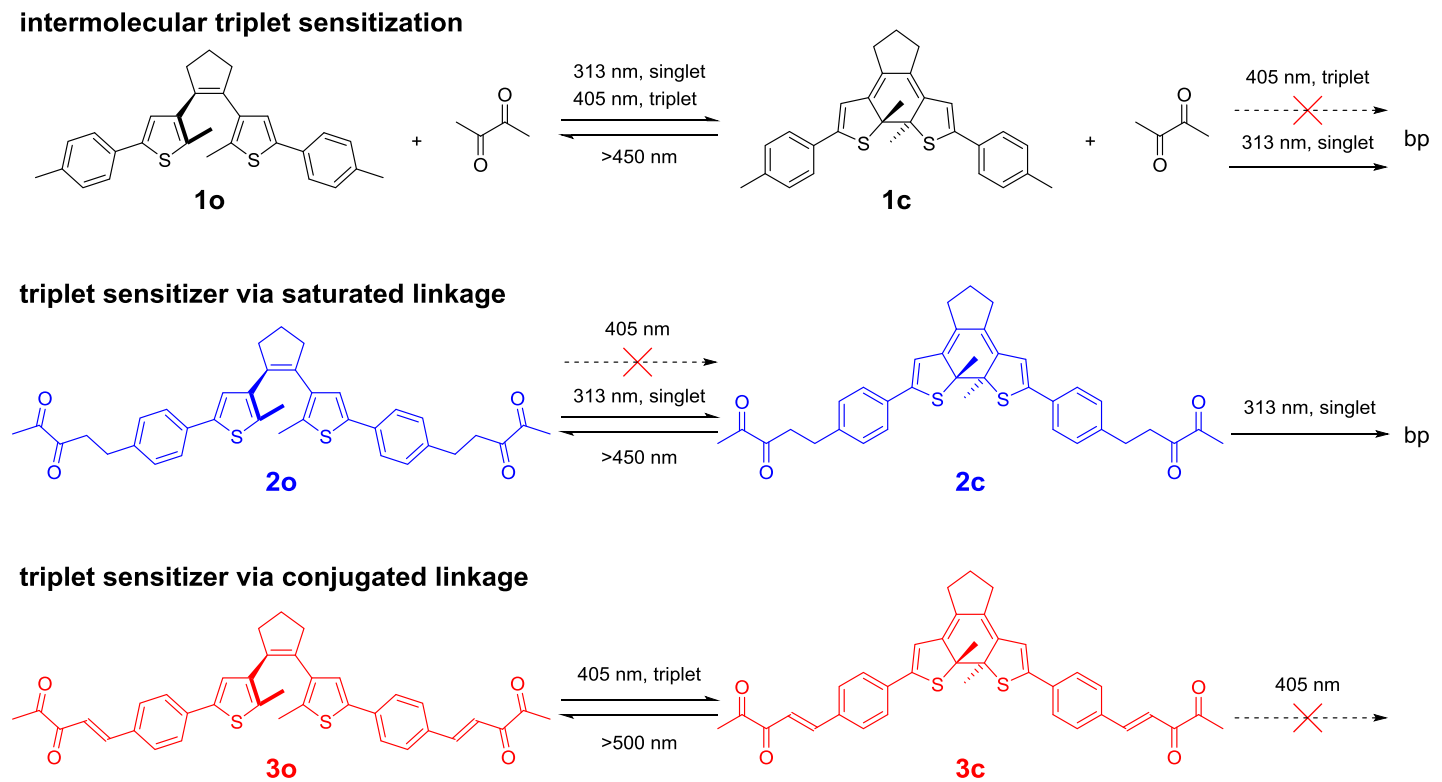

Scheme 1. Evolution of photoswitch design starting from intermolecular triplet sensitization of the parent dithienylethene 1 with biacetyl (top) to intramolecular sensitization via a decoupled system 2 (center) to the best performing $\pi$-conjugated switch 3 (bottom) giving no rise to irreversible byproduct (bp) formation upon visible light (405 nm irradiation.

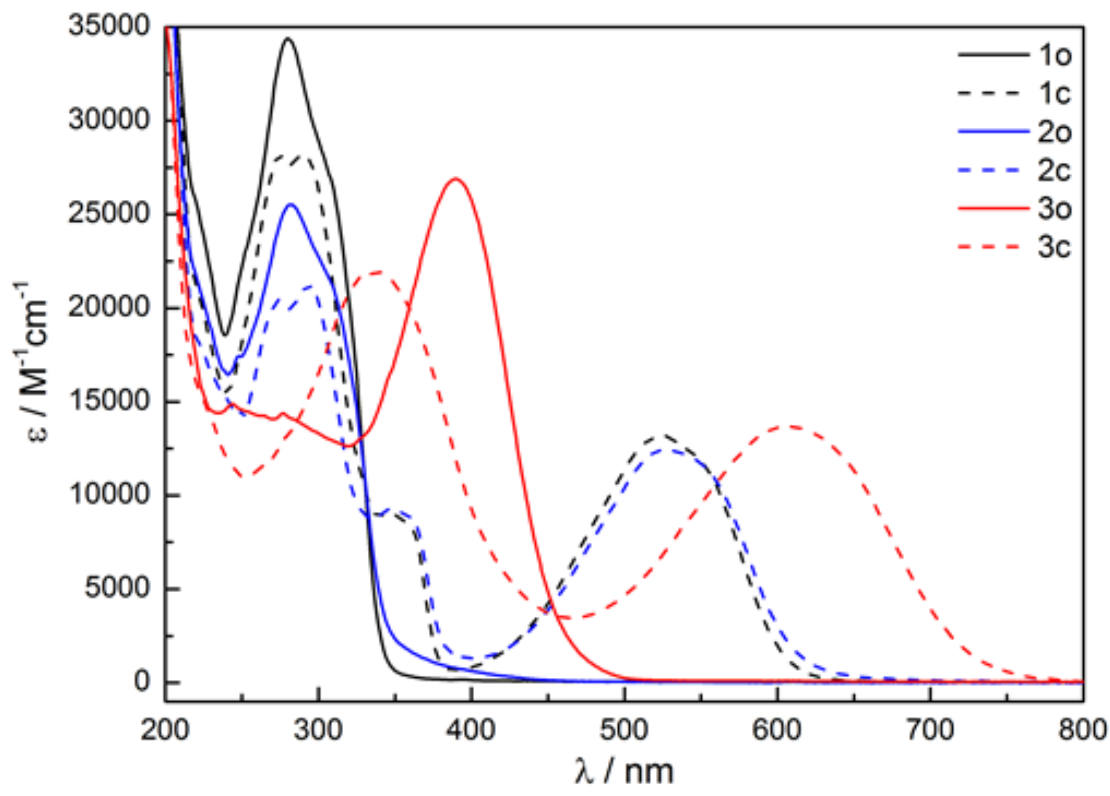

Figure 1. Absorption spectra of the investigated dithienylethenes without biacetyl (1, black), with a saturated linker (2, blue), and with a conjugated linker ( $\mathbf{3}$, red) as their open (solid) as well as closed isomers (dashed) in acetonitrile $\left(2 \times 10^{-5}\right.$ M) at room temperature. 


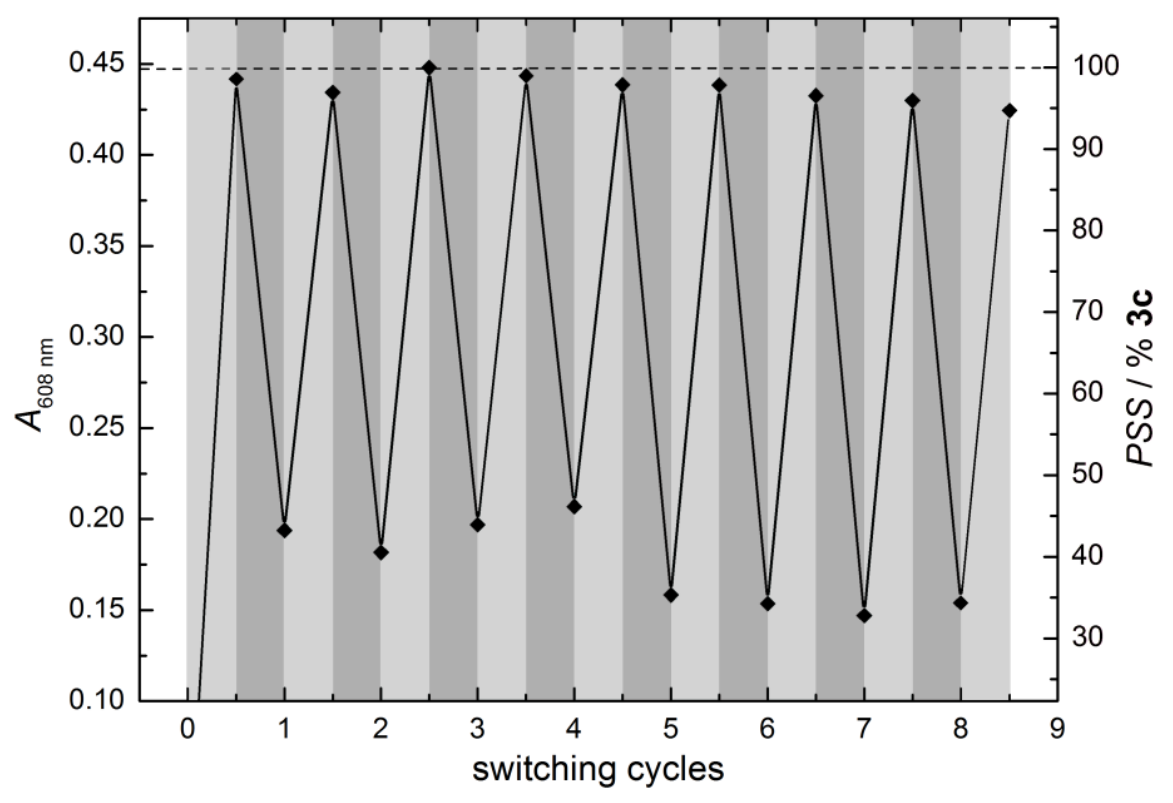

Figure 2. Composition of the photostationary state (PSS, right) as measured by the long-wavelength absorption maximum of $3 \mathbf{c}$ at $608 \mathrm{~nm}$ during alternating switching cycles consisting of ring-closure $(\lambda$ (irr) $=405 \mathrm{~nm}, \mathrm{t}=20 \mathrm{~min}$, light grey areas) and ring-opening $\left(\lambda(\right.$ irr $)=>500 \mathrm{~nm}, \mathrm{t}=100 \mathrm{~min}$, grey areas) of a $2 \times 10^{-5} \mathrm{M}$ degassed acetonitrile solution with a $1000 \mathrm{~W}$ high-pressure Xe lamp. The maximum for pure $\mathbf{3 c}$ is indicated by the dashed line.

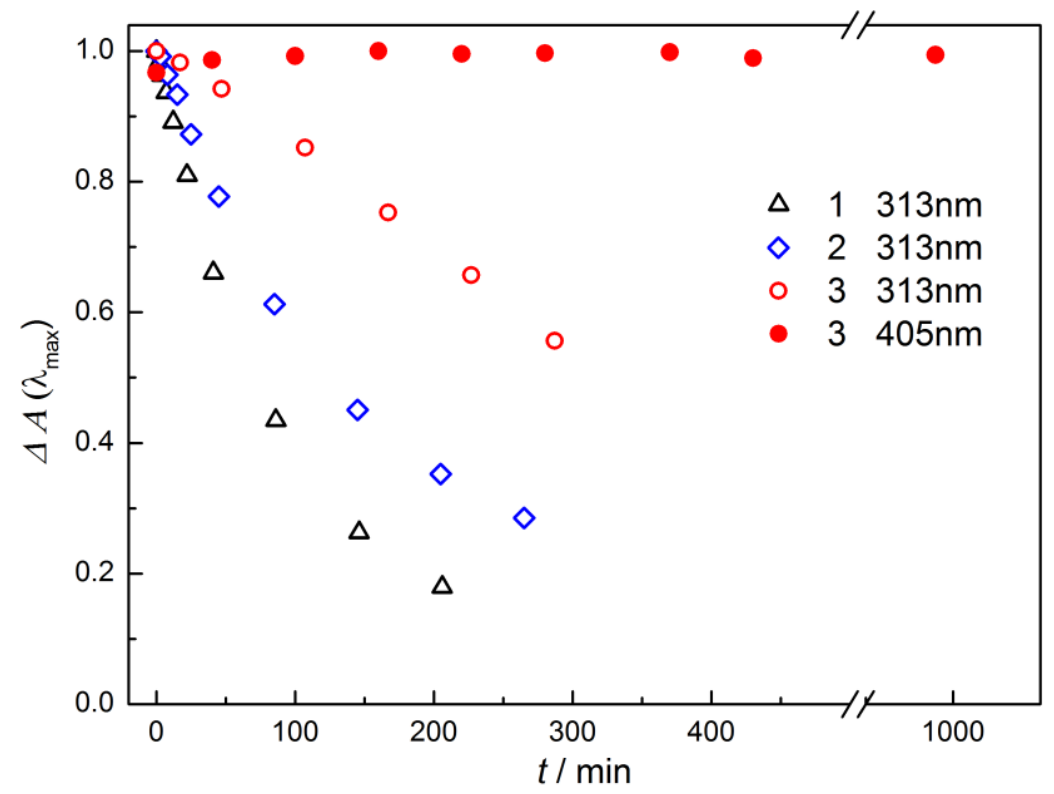

Figure 3. Evolution of the absorbance at the long-wavelength band associated with the ring-closed isomer for the given switches upon constant irradiation with a $1000 \mathrm{~W}$ high-pressure Xe lamp at the depicted wavelengths in degassed acetonitrile solutions $\left(2 \times 10^{-5} \mathrm{M}\right)$. 
Table 1. Quantum yields $(\Phi)$ and composition of the photostationary state (PSS) upon irradiation of the given switch isomers at the depicted wavelengths $(\lambda($ irr $))$ in aerated or degassed acetonitrile $\left(2 \times 10^{-5} \mathrm{M}\right)$ at $25^{\circ} \mathrm{C}$. Biacetyl was added in 250 -fold excess.

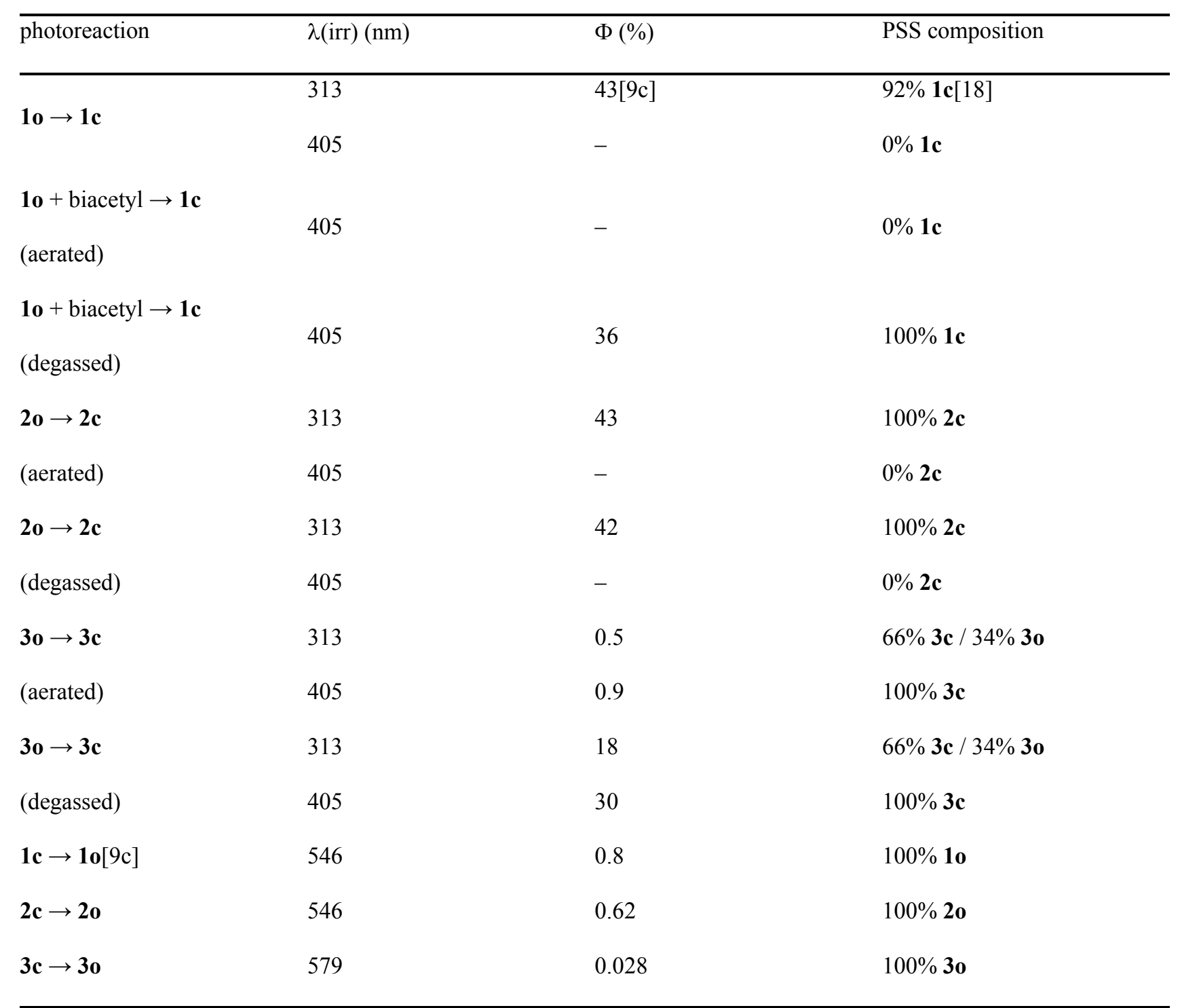

